\title{
Mesoporous Fe-containing ZSM-5 zeolite single crystal catalysts for selective catalytic reduction of nitric oxide by ammonia
}

\author{
L. Kustov ${ }^{\mathrm{a}}$, K. Egeblad ${ }^{\mathrm{a}}$, M. Kustova ${ }^{\mathrm{a}}$, T. W. Hansen ${ }^{\mathrm{b}}$, and C. H. Christensen ${ }^{\mathrm{a}}$, \\ ${ }^{a}$ Center for Sustainable and Green Chemistry, Department of Chemistry, Technical University of \\ Denmark, Building 206, DK-2800 Lyngby, Denmark \\ ${ }^{b}$ Department of Inorganic Chemistry, Fritz Haber Institute of the Max Planck Society, Faradayweg 4-6, \\ 14195 Berlin, Germany \\ * To whom correspondence should be addressed.E-mail: chc@kemi.dtu.dk
}

Mesoporous and conventional Fe-containing ZSM-5 catalysts $(0.5-8 \mathrm{wt} \% \mathrm{Fe})$ were prepared using a simple impregnation method and tested in NO selective catalytic reduction (SCR) with $\mathrm{NH}_{3}$. It was found that mesoporous Fe-ZSM-5 catalysts exhibit higher SCR activities than comparable conventional catalysts. Furthermore, conventional Fe-ZSM-5 catalysts have maximum activity at $\sim 2.5 \mathrm{wt} \% \mathrm{Fe}$ while for the mesoporous system, optimal NO conversion is obtained for the catalysts with $\sim 6 \mathrm{wt} \% \mathrm{Fe}$.

KEY WORDS: DeNOx catalysts; NO SCR with ammonia; mesoporous zeolites; Fe-ZSM-5.

\section{Introduction}

Nitrogen oxides emitted with exhaust gases during the combustion of fossil fuels or biofuels are among the main sources of air pollution. By far the most common method to eliminate $\mathrm{NO}_{\mathrm{x}}$ emissions is selective catalytic reduction (SCR) of NO with ammonia or hydrocarbons. Even though vanadia based catalyst are very active in NO SCR with ammonia and have been commercialized, challenges still remain, e.g. their high activity for oxidation of $\mathrm{SO}_{2}$ to $\mathrm{SO}_{3}$, concerns about the toxicity of vanadia, and the low selectivity of the process at higher temperatures due to competitive $\mathrm{NH}_{3}$ oxidation. Hence there are continuing efforts in developing alternative catalysts. In view of these challenges, the recent discovery of the remarkable activity of over-exchanged Fe-ZSM-5 catalysts in the SCR of NO with isobutene [1] and ammonia [2] was considered a breakthrough. Later it was shown that iron-modified ZSM-5 catalysts prepared by chemical vapor deposition of iron (III) chloride onto the H-form of the zeolite yield high activities most reproducibly [3]. Several recent works have reported very active Fe-ZSM-5 catalysts obtained by the "Improved Liquid Ion Exchange" technique $[4,5]$ as well as by solidstate ion-exchange [6]. A recent publication by Delahay et al. provides a comparative study of Fe-ZSM- 5 SCR catalysts prepared by different methods [7], and a similar comparison has been made earlier by Long and Yang in [5]. However, due to the complicated procedure for the preparation of ion-exchanged Fe-ZSM-5, the large-scale utilization of these catalysts in industry is not expected to be straight-forward. Another important problem, which should be taken into account is a transport phenomenon. Diffusion often limits the activity of the catalysts especially at high reaction rates, which are usually observed in NO SCR with $\mathrm{NH}_{3}$. In the case of traditional vanadia-based catalysts, the SCR reaction is strongly limited by gas-solid interface mass transfer and by slow intraparticle diffusion [8,9]. This ismost probably also the case for the Fe-ZSM-5 zeolite catalysts with channel dimensions within the range of small molecules. And since diffusion through such pores is much slower than in meso- and macropores [10], a possible strategy to circumvent this problem can be the introduction of mesopores into the zeolite structure. 
Recently, a new family of crystalline zeolitic materials was reported, the so-called mesoporous zeolite single crystals [11]. The presence of an intracrystalline mesopore system in these zeolites has in many cases been shown to help solving diffusion problems. In these materials, each individual zeolite single crystal has an additional noncrystalline mesopore system interconnected with the usual micropore system of the zeolite. In some cases, such mesoporous materials also provide better dispersion of the metal component in comparison with conventional microporous systems [12]. Mesoporous zeolite single crystals have previously been reported to show much improved catalytic properties compared to conventional microporous materials for benzene alkylation [13], isomerization and cracking of n-hexadecane [14,15] epoxidation of oct-1-ene and styrene [14] and direct NO decomposition [16]. For the Fe-ZSM-5 catalysts Moulijn, and coworkers [17] have recently shown that a mild alkaline leaching procedure leads to a decrease of the zeolite crystal sizes, and in the case of prolonged treatment, to the formation of a mesopore system. In this case, the rates of $\mathrm{N}_{2} \mathrm{O}$ decomposition increased significantly, which was explained by a better distribution of iron throughout the zeolite material and improved diffusion properties. Here, we report for the first time, the comparative study of the performance of Fe-containing conventional and mesoporous ZSM-5 zeolite single crystal catalysts for the NO SCR with ammonia.

\section{Experimental}

\subsection{Catalyst preparation}

The mesoporous single crystal ZSM-5 zeolite material with $\mathrm{Si} / \mathrm{Al}=50$ was synthesized by crystallizing the zeolite around a carbon matrix which was subsequently removed by combustion, according to the procedure described in [18]. Conventional ZSM-5-type zeolite with $\mathrm{Si} / \mathrm{Al}=50$ was prepared by the standard procedure [19]. The H-form of the corresponding zeolites was prepared according to the procedure described in [15].

Fe-containing HZSM-5 catalysts were prepared by impregnation of the H-form of the zeolite (fraction $0.18-0.295 \mathrm{~mm}$ ) with an aqueous solution of iron nitrate. For impregnation, the incipient wetness method was used. The impregnated samples were dried at room temperature for 2 hours followed by calcination at $450^{\circ} \mathrm{C}$ for $4 \mathrm{~h}$.

\subsection{Catalyst characterization}

The metal content in the samples was measured using atomic absorption spectroscopy. X-ray powder diffraction patterns were recorded for all samples using $\mathrm{CuK}_{\alpha}$ radiation in the $2 \theta$ interval $5-50^{\circ}$ using a Philips powder diffractometer.

Scanning electron microscopy (SEM) was performed on Philips XL20 FEG and Hitachi S-4800 FEG SEMs. For the Philips SEM, the calcined zeolite samples were placed on a carbon film and coated with Pt to achieve better conductivity. For the Hitachi SEM, samples were crushed and deposited on a carbon coated copper grid. No coating of the samples was used. Nitrogen adsorption and desorption measurements were performed at liquid nitrogen temperature on a Micromeritics ASAP 2010. The samples were outgassed in vacuum at $200^{\circ} \mathrm{C}$ prior to measurement. The total surface area was calculated according to the BET method. Meso- and micropore volumes were determined, by the BJH method (desorption). Temperatureprogrammed desorption of ammonia (TPD- $\mathrm{NH}_{3}$ ) was performed by the following procedure: 100 $\mathrm{mg}$ of the sample was loaded into a quartz tube reactor and saturated in a flow of $\mathrm{NH}_{3}$. Prior to $\mathrm{NH}_{3}$ desorption measurement, the sample was heated to $100^{\circ} \mathrm{C}$ in a flow of dry nitrogen (100 $\mathrm{mL} / \mathrm{min}$ ) for $1 \mathrm{~h}$ to remove physically adsorbed ammonia. After that, the sample was cooled to $50^{\circ} \mathrm{C}$, the temperature was ramped to $650^{\circ} \mathrm{C}$ at a $5 \% \mathrm{~min}$. The rate of $\mathrm{NH}_{3}$ desorption was monitored by a computer-interfaced UV-Vis spectrometer using the characteristic ammonia band at $207 \mathrm{~nm}$. The ammonia concentration was calculated based on the intensity of this characteristic band using a calibration curve.

The SCR activity measurements were carried out in a fixed-bed reactor. $50 \mathrm{mg}$ of the catalyst was loaded between two layers of inert quartz wool. The reactant gas composition was $1000 \mathrm{ppm}$ 
$\mathrm{NO}, 1100 \mathrm{ppm} \mathrm{NH} 3,3.5 \% \mathrm{O}_{2}, 3 \% \mathrm{H}_{2} \mathrm{O}$, and balance $\mathrm{N}_{2}$. The total flow rate was maintained at $300 \mathrm{~mL} / \mathrm{min}$ (ambient conditions). The NO concentration was continuously monitored by a Thermo Electron's Model 10A Chemiluminescent NO-NO ${ }_{x}$ Gas Analyzer.

\section{Results and discussion}

According to the X-ray powder diffraction patterns, all conventional and mesoporous ZSM-5 zeolites contain exclusively highly crystalline ZSM-5-type structured materials [20].

In figure 1, the nitrogen adsorption and desorption isotherms and pore size distribution of conventional and mesoporous ZSM-5-type zeolites after combustion of the organic template and carbon black material are given. According to the IUPAC classification of physisorption isotherms [20], conventional ZSM-5 sample has a Type I isotherm typical for microporous materials such as molecular sieve zeolites. The isotherm of mesoporous ZSM-5 sample is a Type IV isotherm. It contains a hysteresis loop at relative pressures higher than $p / p_{0}=0.4$ that is typical for mesoporous materials.

The results of scanning electron microscopy (SEM) of pure conventional and mesoporous HZSM-5-type zeolites and after impregnation with $\sim 4 \%$ iron are shown in figure 2 . The major difference between the conventional and mesoporous zeolite catalysts is the presence of noncrystallographic intracrystalline mesopores resulting in the high porosity and the relatively larger average pore size of the mesoporous zeolite compared to the conventional zeolite. It is clearly seen that iron on the mesoporous catalyst is distributed more homogeneously and forms particles with smaller average diameter, $10-40 \mathrm{~nm}$, than in the case of the conventional zeolite where the iron particles are $10-80 \mathrm{~nm}$.

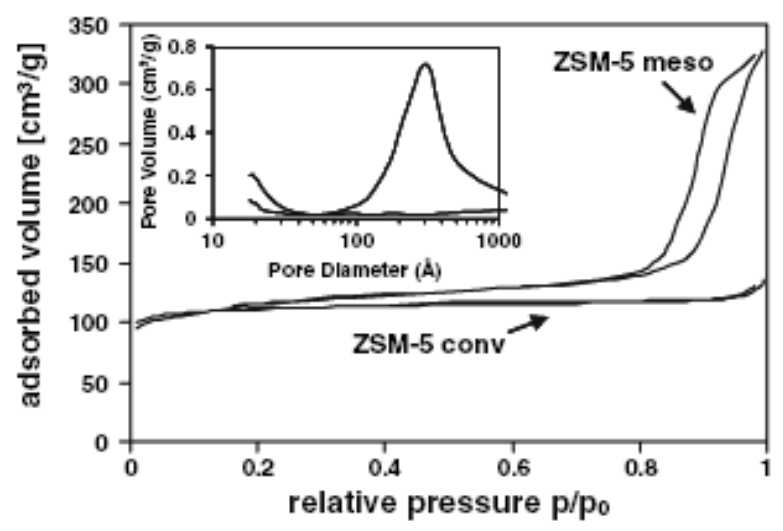

Figure 1. Nitrogen adsorption and desorption isotherms and pore size distribution of conventional and mesoporous ZSM-5-type zeolites.

The iron content and the amounts of desorbed $\mathrm{NH}_{3}$ for the pure zeolites and after loading with iron are listed in the table 1. Catalysts are designated according to their Fe content; the designator in parenthesis indicates whether it is a conventional (c) or mesoporous (m) sample. Even though the BET equation is not valid for micropores it is still possible to use BET areas obtained for similar systems for the comparative purposes. The main conclusion from these data is that all mesoporous and conventional zeolites have approximately the same surface areas; therefore, it is fair to compare their catalytic properties without normalizing to the surface area. The same BET areas after loading with iron also indicate that introduction of iron does not lead to a significant blocking of the zeolite internal surface by iron oxide particles. 

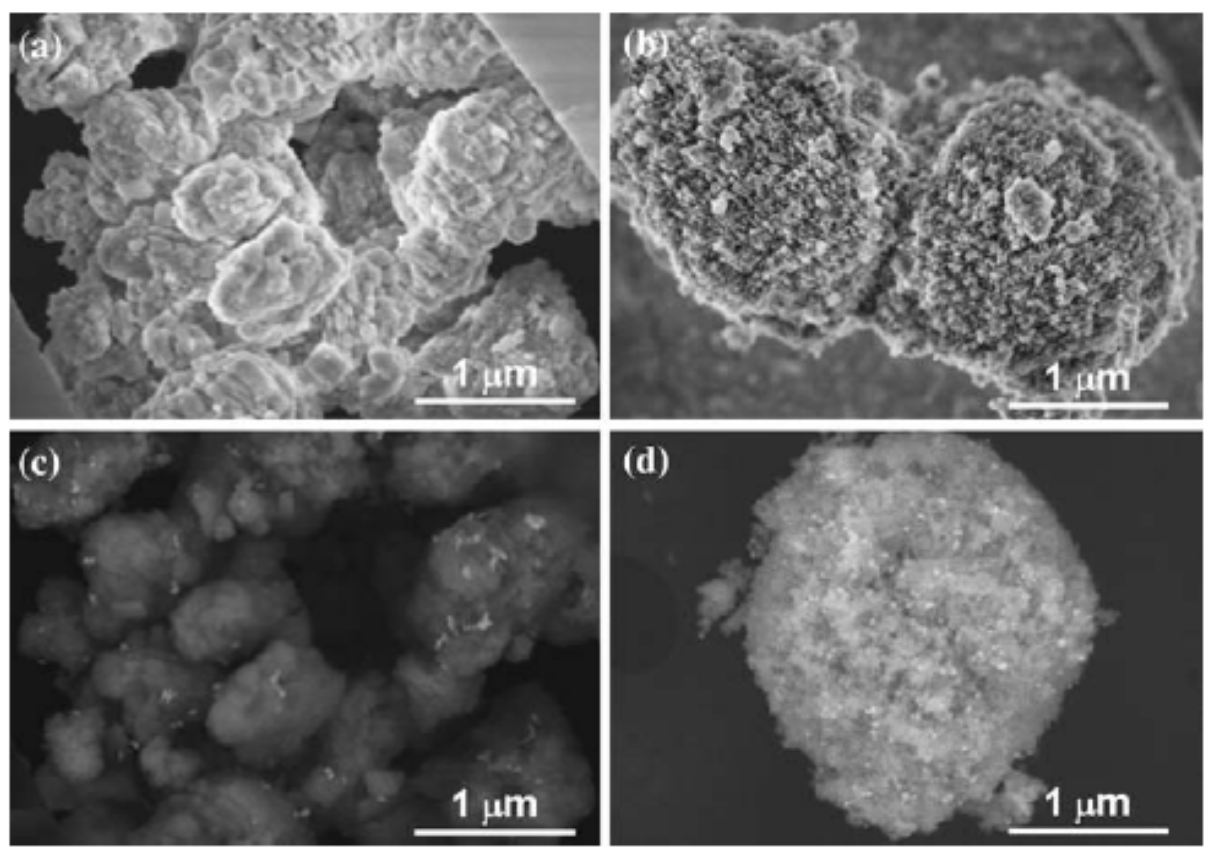

Figure 2. SEM images of conventional (a) and mesoporous (b) HZSM-5-type zeolites, and conventional (c) and mesoporous (d) FeZSM-5 zeolites with 4 wt $\%$ Fe.

Table 1

Iron content, BET surface area and amount of desorbed ammonia for the samples employed in the present study

\begin{tabular}{|c|c|c|c|}
\hline Sample & $\begin{array}{c}\text { Iron content } \\
(\mathrm{wt} \%)\end{array}$ & $\begin{array}{c}\text { BET surface area } \\
(\mathrm{m} 2 / \mathrm{g})\end{array}$ & $\begin{array}{c}\mathrm{NH}_{3} \text { desorbed } \\
(\mu \mathrm{l} \mathrm{mol} / \mathrm{g})\end{array}$ \\
\hline HZSM-5 $(\mathrm{c})$ & - & 390 & 1056 \\
\hline $0.5 \% \mathrm{Fe} / \mathrm{HZSM}-5(\mathrm{c})$ & 0.45 & 382 & 1030 \\
\hline $1.4 \% \mathrm{Fe} / \mathrm{HZSM}-5(\mathrm{c})$ & 1.43 & 375 & 1016 \\
\hline $2.4 \% \mathrm{Fe} / \mathrm{HZSM}-5(\mathrm{c})$ & 2.40 & 368 & 976 \\
\hline $3.6 \% \mathrm{Fe} / \mathrm{HZSM}-5(\mathrm{c})$ & 3.61 & 344 & 964 \\
\hline $4.9 \% \mathrm{Fe} / \mathrm{HZSM}-5(\mathrm{c})$ & 4.89 & 336 & 808 \\
\hline $5.9 \% \mathrm{Fe} / \mathrm{HZSM}-5(\mathrm{c})$ & 5.92 & 325 & 694 \\
\hline HZSM-5 $(\mathrm{m})$ & - & 389 & 585 \\
\hline $0.6 \% \mathrm{Fe} / \mathrm{HZSM}-5(\mathrm{~m})$ & 0.59 & 385 & 577 \\
\hline $1.5 \% \mathrm{Fe} / \mathrm{HZSM}-5(\mathrm{~m})$ & 1.47 & 383 & 569 \\
\hline $2.9 \% \mathrm{Fe} / \mathrm{HZSM}-5(\mathrm{~m})$ & 2.86 & 376 & 552 \\
\hline $4.0 \% \mathrm{Fe} / \mathrm{HZSM}-5(\mathrm{~m})$ & 3.97 & 368 & 496 \\
\hline $5.2 \% \mathrm{Fe} / \mathrm{HZSM}-5(\mathrm{~m})$ & 5.21 & 361 & 450 \\
\hline $6.1 \% \mathrm{Fe} / \mathrm{HZSM}-5(\mathrm{~m})$ & 6.05 & 355 & \\
\hline
\end{tabular}

According to the $\mathrm{NH}_{3}$-TPD measurements the introduction of Fe does not influence the acidity significantly. This indicates that in the case of simple impregnation followed by calcination, predominantly iron oxide species are formed. In other words, essentially no competitive ionexchange takes place, as was observed by Yang in [5] when calcining annealing $\mathrm{NH}_{4} \mathrm{ZSM}-5$ freshly impregnated with iron salt in $\mathrm{He}$. The $\mathrm{NH}_{3}$ - TPD results also indicate that introduction of 
iron does not create new sites for the ammonia adsorption, since the acidity does not change and even slightly decreases with increasing Fe loading. In fact, a slight decrease in the acidity could probably be explained by partial blocking of the acid sites of the zeolite due to the formation of iron oxide particles. Lower values of desorbed ammonia for mesoporous zeolite are related with the fact that during preparation procedure not all alumina introduced with the synthesis gel is finally present in the zeolite framework. Some part is present as extraframework alumina particles and, therefore, does not produce acid sites for the ammonia adsorption. Figure 3 shows the temperature dependence of the NO conversion obtained in NO SCR with ammonia for conventional and mesoporous Fe/HZSM-5 catalysts. With increasing reaction temperature, the NO conversion increases in all cases. However, for catalysts with Fe content higher than $2.5 \%$, the activity passes through a maximum due to competitive ammonia oxidation at higher temperatures.
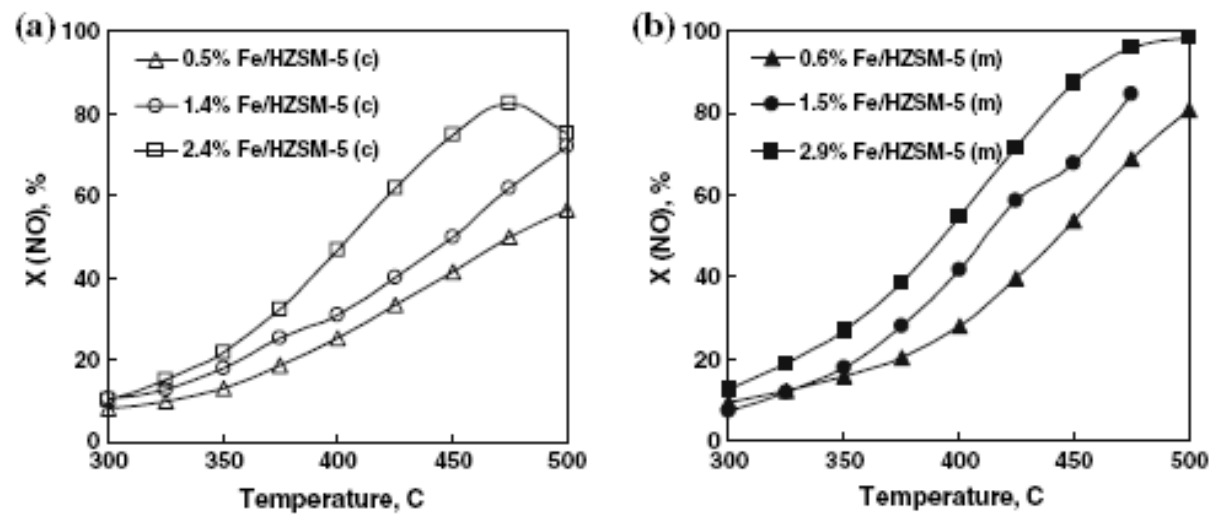

Figure 3. Temperature dependency of the NO conversions in SCR with ammonia for conventional (a) and mesoporous (b) Fe/HZSM-5 catalysts. Reaction conditions: $50 \mathrm{mg}$ of the catalyst, $1000 \mathrm{ppm} \mathrm{NO}, 1100 \mathrm{ppm} \mathrm{NH}_{3}$, $3.5 \% \mathrm{O}_{2}, 3 \% \mathrm{H}_{2} \mathrm{O}$ balanced with $\mathrm{N}_{2}$ (total flow rate $300 \mathrm{~mL} / \mathrm{min}$ ).

It is noteworthy that for conventional and mesoporous samples with similar iron loading, mesoporous catalysts are more active than conventional in the entire temperature interval. The difference is most pronounced at high reaction rates, which can be a result of the significantly better diffusion of reactants and/or products in the mesopores. By increasing the iron content in the catalysts up to $3 \mathrm{wt} \%$, the NO conversion increases for both conventional and mesoporous samples. Further increase in the iron content does not improve catalytic activity for the conventional samples. Figure 4 illustrates the influence of the Fe loading on the SCR activities for conventional and mesoporous samples. It can be seen that the activity of the mesoporous catalyst gradually increases with increasing $\mathrm{Fe}$ content, and reaches a maximum at approximately $6 \mathrm{wt} \%$ Fe. For the conventional Fe/HZSM-5 samples, maximum activity is observed at much lower Fe loadings. This result can be related to the better dispersion of iron species possible in the mesoporous samples as was confirmed by SEM. For the comparison, 3\% $\mathrm{V}_{2} \mathrm{O}_{5} / \mathrm{TiO}_{2}$ reference catalyst under the same reaction conditions shows $90 \% \mathrm{NO}$ conversion at $350^{\circ} \mathrm{C}$ which is of course significantly higher than the most active $6 \% \mathrm{Fe} / \mathrm{H}-\mathrm{ZSM}-5(\mathrm{~m})$ catalyst, but if we compare the activities of these two catalyst at $400^{\circ} \mathrm{C}$ mesoporous catalyst is as good as the reference catalyst: $98 \%$ versus $97 \%$ respectively. At $450^{\circ} \mathrm{C}$ mesoporous catalyst is even more active: $93 \%$ against $86 \%$ for $3 \% \mathrm{~V}_{2} \mathrm{O}_{5} / \mathrm{TiO}_{2}$. 


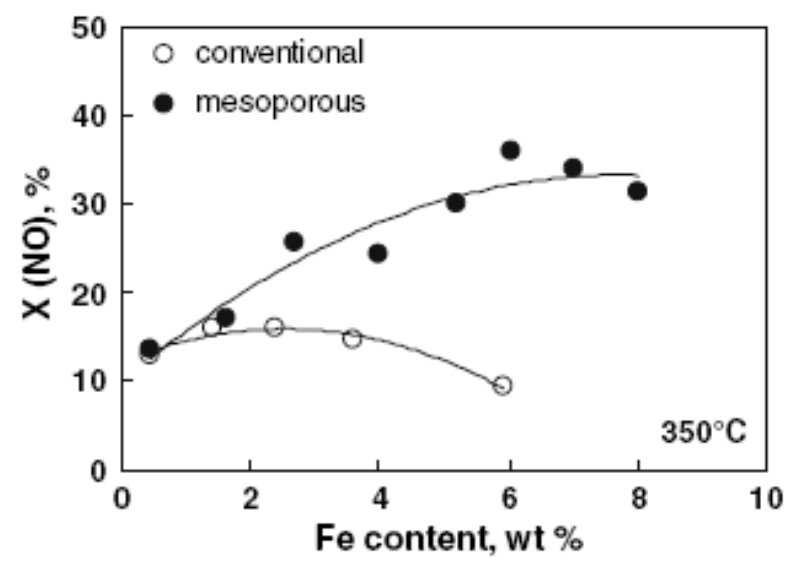

Figure 4. Effect of Fe loading on NO conversion over conventional ( $(\circ)$ and mesoporous (•) Fe/HZSM-5 catalysts. Reaction conditions: $50 \mathrm{mg}$ of the catalyst, $\mathrm{T}=350^{\circ} \mathrm{C}, 1000 \mathrm{ppm} \mathrm{NO}, 1100 \mathrm{ppm} \mathrm{NH}, 3.5 \% \mathrm{O}_{2}, 3 \% \mathrm{H}_{2} \mathrm{O}$ balanced with $\mathrm{N}_{2}$ (total flow rate $300 \mathrm{~mL} / \mathrm{min}$ ).

It should be also mentioned that the catalysts tested in this work have lower catalytic activity than the overexchanged Fe-ZSM-5 catalysts prepared by chemical vapor deposition [3] or "Improved Liquid Ion Exchange"' technique [4,5] However, due to the complicated procedure for the preparation of ion-exchanged Fe-ZSM-5 and lack or reproducibility, the large-scale utilization of these catalysts in industry is limited. Therefore we first apply very simple method of incipient wetness impregnation, which, in contrast to the ionexchange procedure, enables us to introduce active component in more controlled way, which is more important for the fair comparison of the conventional and mesoporous samples. The combination of mesoporous zeolite support and more advanced methods of introducing iron into the zeolite structure will apparently allow us to obtain even more active SCR catalysts and this subject require further investigations.

\section{Conclusions}

A series of mesoporous and conventional Fe/HZSM- 5 catalyst with different iron content was prepared using simple impregnation procedure. It was shown that for the catalysts with similar Fe content activity of mesoporous samples in NO SCR with $\mathrm{NH}_{3}$ is significantly higher than for conventional samples, especially at high reaction rates, which can be explained by the better diffusion of reactants and products in the mesopores. Conventional Fe/HZSM-5 samples have a maximum catalytic activity at $\sim 2.5 \mathrm{wt} \% \mathrm{Fe}$ while for the mesoporous samples $\mathrm{NO}$ conversion increases quite significantly when increasing the Fe content from 1 up to $6 \mathrm{wt} \%$, which is related to the better dispersion of iron species in the mesoporous samples. The results of this study show that by use of very simple impregnation procedure it is possible to obtain active SCR catalysts, which are even more active than reference vanadia based catalyst at temperatures above $400^{\circ} \mathrm{C}$.

\section{Acknowledgments}

The Center for Sustainable and Green Chemistry is sponsored by the Danish National Research Foundation. We acknowledge the support of the Danish Research Agency (grant 26-04-0047).

References

[1] X. Feng and W.K. Hall, Catal. Lett. 41 (1996) 45.

[2] R.Q. Long and R.T. Yang, J. Catal. 188 (1999) 332.

[3] H.-Y. Chen and W.M.H. Sachtler, Catal. Today 42 (1998) 73.

[4] M. Schwideder, M.S. Kumar, K. Klementiev, M.M. Pohl, A. Bru“ ckner and W Gru“ nert, J. Catal. $231(2005) 314$.

[5] R.Q. Long and R.T. Yang, Catal. Lett. 74 (2001) 201. 
[6] G. Qi and R.T. Yang, Appl Catal. B 60 (2005) 13.

[7] G. Delahay, D. Valade, A. Guzma' n-Vargas and B. Coq, Appl. Catal. B 55 (2005) 149.

[8] J.W. Beeckman and L.L. Hegedus, Ind. Eng. Chem. Res. 30 (1991) 969.

[9] J. Svachula, N. Ferlazzo, P. Forzatti and E. Tronconi, Ind. Eng. Chem. Res. 32 (1993) 1053.

[10] A Corma, Chem. Rev. 95 (1995) 559.

[11] C.J.H. Jacobsen, C. Madsen, J. Houzvicka, I. Schmidt and A. Carlsson, J. Am. Chem. Soc. 122 (2000) 7116.

[12] C.H. Christensen, I. Schmidt, A. Carlsson, K. Johannsen and K. Herbst, J. Am. Chem. Soc. 127 (2005) 8098.

[13] C.H. Christensen, K. Johannsen, I. Schmidt and C.H. Christensen, J. Am. Chem. Soc. 125 (2003) 13370.

[14] M.Yu. Kustova, P. Hasselriis and C.H. Christensen, Catal. Lett. 96 (2004) 205.

[15] C.H. Christensen, I. Schmidt and C.H. Christensen, Catal. Commun. 5 (2004) 543.

[16] M.Yu. Kustova, S.B. Rasmussen, A.L. Kustov and C.H. Christensen,Appl. Catal. B 67 (2006) 60.

[17] I. Melian-Cabrera, S. Espinosa, J.C. Groen, B. Linden, F. Kapteijn and J.A. Moulijn, J. Catal. 238 (2006) 250.

[18] M.Yu. Kustova, A.L. Kustov and C.H. Christensen, Stud. Surf. Sci. Catal. 158 (2005) 255.

[19] M.Yu. Kustova, A.L. Kustov, S.E. Christiansen, K.T. Leth, S.B. Rasmussen and C.H. Christensen, Catal. Commun. 7 (2006) 705.

[20] Database of zeolite structures: http://www.iza-structure.org/databases/. 